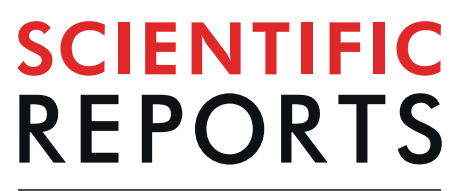

natureresearch

\title{
Streptococcus gallolyticus abrogates anti-carcinogenic properties of tannic acid on low- passage colorectal carcinomas
}

\author{
Sonja Oehmcke-Hecht ${ }^{1 *}$, Vanessa Mandl ${ }^{1,2}$, Lukas Tim Naatz ${ }^{1,2}$, Lara Dühring ${ }^{1,2}$, \\ Juliane Köhler ${ }^{1}$, Bernd Kreikemeyer ${ }^{1} \&$ Claudia Maletzki ${ }^{2 *}$
}

The tannase-producing Gram-positive bacterial species Streptococcus gallolyticus subsp. gallolyticus $(\mathrm{Sgg})$ is an opportunistic pathogen of the human gut and strongly associated with colorectal cancer (CRC). A unique feature of Sgg is its ability to degrade tannic acids (TA). TA constitute an important part of the human diet with known anti-tumorigenic properties. Here, we examined whether Sgg is able to protect tumor cells from the toxic effect of TA and thus drive tumorigenesis indirectly. Human CRC cell lines $(n=8)$ were treated with increasing concentrations of TA. We confirmed the cytotoxic activity of TA in a dose-dependent manner. In virtually all cell lines, viability decreased significantly $(>60 \%$ inhibition). Moreover, pyrogallol, the degradation product ofTA, had no effect on the tested cell lines. This suggests a specific effect of TA. Cytotoxicity was due to necrosis and induction of senescence in residual cells. Finally, when TA was degraded by Sgg, the cytotoxic effect could be abolished. Tumor cells even responded with boosted cell proliferation, highlighting the impact of Sgg on CRC progression. We here provide another piece of evidence for the active interplay between Sgg and cancer preventive components. These data will help to move forward in designing concepts for therapeutic and eventually also prophylactic approaches to combat gastrointestinal malignancies.

The opportunistic pathobiont Streptococcus gallolyticus subsp. gallolyticus (Sgg), previously known as Streptococcus bovis biotype I, is asymptomatically found in the gastrointestinal tract of humans $(2.5-15 \%)$, ruminants and birds. The bacteria belong to the Streptococcus bovis/Streptococcus equinus complex (SBSEC) ${ }^{1}$, a highly diverse bacterial group of Gram-positive, non-hemolytic Lancefield group D commensals. The original division of the SBSEC into S. bovis and S. equinus has further changed over the past years, reaching the current splitting into seven main (sub)species, Streptococcus infantarius subsp. infantarius (Sii), Streptococcus lutetiensis, Streptococcus gallolyticus subsp. pasteurianus (Sgp), Streptococcus gallolyticus subsp. macedonicus (Sgm), Streptococcus gallolyticus subsp. gallolyticus (Sgg), Streptococcus alactolyticus and S. equinus ${ }^{1-3}$. Sgg is estimated to be the causative agent of endocarditis in 11-14\% of cases ${ }^{4}$. Interestingly, multiple studies have shown that endocarditis due to Sgg is often associated with gastrointestinal malignancy ${ }^{5}$. Colonization of the gut by $\mathrm{Sgg}$ is related to the occurrence of colorectal cancer (CRC), the presence of $S g g$ in CRC patients with up to $74 \%$ is much higher than in healthy people ${ }^{6,7}$. It has been suggested that $S g g$ itself may play a causal role in CRC development, as the bacteria promote tumor proliferation by upregulating $\beta$-catenin ${ }^{8}$.

On the other hand, it was previously shown that CRC-specific conditions - namely the increased concentration of bile acids - promote $\mathrm{Sgg}$ colonization, as secondary bile acids strongly enhanced activity of a bacteriocin (gallocin) that is produced by the bacteria ${ }^{9}$. Further on, Sgg is remarkably resistant to bile acids ${ }^{10}$. Another distinctive characteristic of $S g g$ is its ability to degrade tannic acids (also named "gallotannin"), a property, which led this bacterium to be named "gallolyticus"11. Tannic acid (TA) belongs to the family of hydrolysable tannins. It is found in a variety of fruits and beverages, such as tea, coffee and red wine, thus TA constitutes an important part of the human diet ${ }^{12,13}$. Moreover, TA inhibits the proliferation of diverse tumor cells, including CRC, without

${ }^{1}$ Institute of Medical Microbiology, Virology and Hygiene, Rostock University Medical Center, Rostock, Germany. ${ }^{2}$ Department of Internal Medicine, Medical Clinic III - Hematology, Oncology, Palliative Care, Rostock University Medical Center, Rostock, Germany. *email: sonja.oehmcke-hecht@med.uni-rostock.de; claudia.maletzki@med. uni-rostock.de 
being toxic to normal cells ${ }^{14,15}$. TA constrains the expression of inflammatory genes and cytokines in human lung cancer cells ${ }^{16}$, and has anti-metastatic potential ${ }^{17}$. Finally, it was shown recently that TA inhibits telomerase activity in vitro and in vivo ${ }^{18-20}$.

Intriguingly, especially bacteria that selectively colonize tumorous tissues in CRC patients - but not adjacent non-malignant tissues - contain tannase homologous genes ${ }^{21}$, which allows them to degrade TA. In contrast, the closely related (sub)species Streptococcus infantarius subsp. infantarius (Sii) have lost genes for detoxifying toxic substances such as TA ${ }^{22}$. Sgg hydrolyze TA by tannase into gallic acid. Gallic acid will be decarboxylated by a gallate decarboxylase to pyrogallol $(\mathrm{PG})^{23}$. Of note, Jiménez et al. considered Sgg as the best bacterial cellular factories for (gallo)tannin degradation so far known ${ }^{24}$.

We therefore hypothesized whether this special feature of Sgg might protect the tumor cells from the toxic effect of TA. We could show that all of the investigated low passaged CRC cell lines are susceptible towards TA treatment. Moreover, PG, the degradation product of TA, had no cytotoxic effect on the tested cell lines. Finally, when TA was degraded by Sgg, the toxic effect on the tumor cells could be abolished. This supports the assumption that colonization of the tumor by Sgg protects the tumor cells against otherwise toxic plant components that will be consumed by a normal human diet.

\section{Methods}

Tumor cell lines and culture media. CRC cell lines HROC24 T1 M1, HROC60, HROC173, HROC183 T0 M2, HROC257 T0 M1, HROC285 T0 M2, HROC324, and HROC370 were described before and obtained from Cell line services (Eppelheim, Germany) ${ }^{25}$. The CRC cell lines HT29 and CaCo2 were originally obtained from the German collection of cell cultures (DSMZ; Braunschweig, Germany) and routinely cultured in our lab. Cells were maintained in full medium: DMEM/HamsF12 supplemented with 10\% fetal calf serum (FCS), glutamine $(2 \mathrm{mmol} / \mathrm{L})$ and antibiotics (medium and supplements were purchased from PAA, Cölbe, Germany).

Bacterial strain and culture conditions. Sgg UCN34 was isolated at the Hospital in Caen (Calvados, France $)^{26}$. Sii JIM 9407 was isolated from human origin in Africa ${ }^{27}$. Bacteria were grown on blood agar plates at $37^{\circ} \mathrm{C}$, aerobically, overnight and subsequently stored at $4^{\circ} \mathrm{C}$. For further use, overnight cultures were cultivated in BHI broth at $37^{\circ} \mathrm{C}$ under a $5 \% \mathrm{CO}_{2}-20 \% \mathrm{O}_{2}$ atmosphere in the presence or absence of TA (Sigma Aldrich, Germany). The optical density was determined in a Spectramax (Molecular Devices, USA) or the bacteria were plated every hour to determine the $\mathrm{CFU} / \mathrm{ml}$.

Treatment protocol. CRC cell lines ( 8 in total) were treated with increasing TA or PG concentrations (ranging from 2.5 to $100 \mu \mathrm{M}$ ) for $72 \mathrm{~h}$. Thereafter, selected cell lines were used for different experiments. Bacterial supernatants from TA degradation experiments were diluted 1:10 in cell culture medium before applied to the cells.

Flow cytometric DNA analysis and crystal violet staining. Cells were grown to about $70 \%$ confluence in 24-well culture plates and then incubated in complete medium with or without TA and PG for 72 hours, respectively. Subsequently, cells were prepared for crystal violet staining, as well as flow cytometric apoptosis and cell cycle analysis as reported previously ${ }^{28}$. Additionally, a Yo-Pro-1/PI-based assay for discriminating (early) apoptotic and necrotic cells was applied as described before ${ }^{25}$.

Wound healing assay. Tumor cell proliferation after TA or PG treatment was investigated as described befor ${ }^{29}$ Briefly, cells were seeded in 6-well plates and grown to $100 \%$ confluency. Monolayers were scratched with a $20 \mu \mathrm{L}$ pipette tip to induce a wound. Wounded edges were imaged using a Zeiss inverted microscope. Images were taken daily for a period of $5 \mathrm{~d}$ under a $\times 10$ objective lens.

Measurement of cellular senescence. Induction of senescence after 5 days of treatment with TA or PG was measured by $\beta$-galactosidase, detectable at $\mathrm{pH} 6.0$ with the artificial substrate $\mathrm{X}$-gal ${ }^{30}$.

Determination of tannase activity. Tannase activity of Sgg UCN34 or Sii was determined by a spectrophotometric method ${ }^{31}$. Briefly, overnight cultures of bacteria were set to $10^{8} \mathrm{CFU} / \mathrm{ml}$ in PBS and incubated with $2 \mathrm{mM}$ methylgallate for $24 \mathrm{~h}$ at $37^{\circ} \mathrm{C}$. After $24 \mathrm{~h}$ of incubation, $0.5 \mathrm{ml}$ of the suspension were alkalinized with equal amounts of saturated $\mathrm{NaHCO}_{3}$ solution $(\mathrm{pH}$ 8.6) and then left in the atmosphere at room temperature for 60 min. This alkalization facilitated nonenzymatic oxidation of gallic acid (released by tannase from methylgallate) to form polymerized compounds of o-quinone derivatives, resulting in green to brown coloration of the medium. Absorption was measured at $440 \mathrm{~nm}$.

Degradation of TA by Sgg or Sii. Overnight cultures of bacteria were set to $10^{8} \mathrm{CFU} / \mathrm{ml}$ in PBS and incubated with $1 \mathrm{mM}$ TA at $37^{\circ} \mathrm{C}$ for $24-48 \mathrm{~h}$. As control TA solution $(1 \mathrm{mM})$ without bacteria was used. Absorption of TA was measured at $310 \mathrm{~nm}$. Bacterial supernatants for incubations on cells were sterilfiltered and stored at $-20^{\circ} \mathrm{C}$ until use.

Statistics. All values are reported as mean \pm SD. After proving the assumption of normality, differences between controls and treated cells were determined by using the unpaired Student's $t$-test. If normality failed, the non-parametric Mann-Whitney $U$-Test was applied. In case of multiple comparisons, one way ANOVA on ranks (Bonferroni’s Multiple Comparison Test or Holm-Šídák) was applied. Statistical evaluation was performed using GraphPad PRISM software, version 5.02 (GraphPad Software, San Diego, CA, USA). The criterion for significance was taken to be $\mathrm{p}<0.05$. 

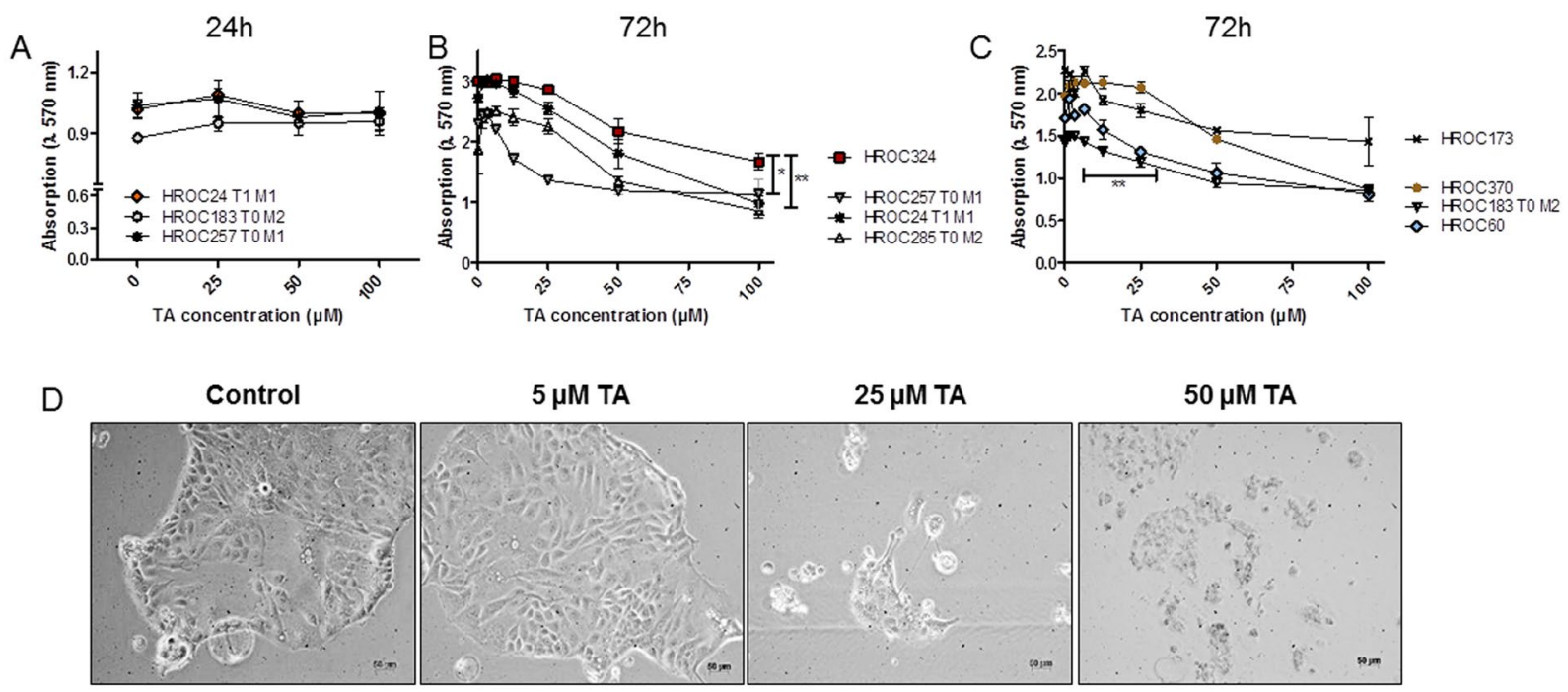

Figure 1. Crystal violet staining and morphology of cell lines treated with increasing doses of TA. (A-C) Quantitative analysis of adherent cells upon (A) 24 hours and (B,C) 72 hours of treatment. Untreated cells were used as controls. TA reduced cell growth of different patient-derived CRC cell lines in a dose-dependent manner. Results show data of three independent experiments. Mean \pm SD. **p $=0.0065$ HROC257 T1 M1 vs. HROC324; $\mathrm{p}=0.0259$ HROC285 T0 M2 vs. HROC324, **p =0.0071 HROC183 T0 M2 vs. HROC370; two-tailed t-test. (D) Light microscopy of HROC285 T0 M2 cells after $72 \mathrm{~h}$ treatment with increasing TA concentrations. $1 \times 10^{4}$ cells were seeded and after overnight incubation treated with different concentrations of TA. Pictures were taken $72 \mathrm{~h}$ after treatment.

\section{Results}

Growth inhibition of low passage CRC cell lines by TA. To investigate the susceptibility of CRC cell lines against TA, 8 patient-derived low passage CRC cell lines were treated with increasing TA concentrations. Following 24, 48, and 72 hours of incubation, biomass was quantified by crystal violet staining (Fig. 1A-C). TA reduced the biomass time-dependently with significant inhibition after 72 hours at a concentration of $12.5 \mu \mathrm{M}$ (Fig. 1B,C). Of note, minor differences were observed between individual cell lines.

Microscopic observation confirmed these data with a destroyed cell layer and dead cells after $72 \mathrm{~h}$ of incubation with $25 \mu \mathrm{M}$ TA (Fig. 1D shows exemplary images of HROC285 T0 M2 cells). PG is a degradation product of $\mathrm{TA}$, with potential cytotoxic activity. However, even at high concentrations $(100 \mu \mathrm{M})$, no significant reduction of biomass was measured in different cell lines (Fig. 2). Of note, no differences were seen between low (HROC173, HROC257 T0 M1) and high passage (HT29, CaCo-2) cells (Fig. 2).

TA induces predominantly necrosis in target cells. To improve our understanding on the type of cell death induced by TA, 6 CRC cell lines ( 5 low and 1 high passage) were subjected to flow cytometric apoptosis/necrosis analysis. We observed predominantly necrosis in all cell lines (Fig. 3A-F; 3G: exemplary results of HROC173 cells). Levels of necrotic tumor cells, as defined by positive PI staining, increased significantly by about $10-40 \%$ in the different cell lines after treatment with TA (Fig. 3). Late apoptotic cells, being Yo-Pro- $1^{+} / \mathrm{PI}^{+}$were below $10 \%$ in the controls, and additionally reduced after incubation with TA in 5/6 cell lines. The only exception was seen in HROC324; showing increased numbers of apoptotic cells (Fig. 3D). Complementary examination of cell cycle principally confirmed these findings. While most of the cells showed elevated levels of sub-G1 DNA (up to $50 \%$; HROC257 T0 M1 $72 \mathrm{~h}: \mathrm{p}<0.01 \mathrm{TA} 100 \mu \mathrm{M}$ vs. ctrl and vs. TA $5 \mu \mathrm{M}$; p $<0.05$ TA $25 \mu \mathrm{M}$ vs. ctrl), residual cells were either arrested in G1 or mainly in G2/M-phase (Fig. 4).

Influence of TA and PG on senescence, invasion and migration. TA was previously described to induce senescence in the CRC cell line HCT $116^{32}$. Thus, we assessed the potential of TA to induce senescence in four selected cell lines (low passage: HROC173, HROC257 T0 M1; high passage: HT29, CaCo-2) after 5 days of incubation with $50 \mu \mathrm{M}$ TA or PG. For all cell lines, induction of senescence was observed. Figure $5 \mathrm{~A}$ shows exemplary images of HROC173 and HROC257 T0 M1, along with quantitative analysis depicted in Fig. 5B. As expected, PG had no effect on the cells (Fig. 5, middle panel), while TA led to a significant increase in senescent cells $(\mathrm{p}<0.0001$ vs. ctrl, Fig. 5B).

Next, a wound healing assay was used to examine proliferation in the presence of TA or PG (Fig. 6). Representative pictures of low passage cell lines HROC173 (Fig. 6A-D) and HROC257 T0 M1 (Fig. 6E-H) are given. While control cells proliferated and closed the wound within 5 days (Fig. 6B,F), cells treated with $50 \mu \mathrm{M}$ TA did not proliferate, the cell layer was destroyed and remaining cells looked unhealthy (Fig. 6C,G). PG had no inhibiting effect on proliferation, the wound was fully closed within 5 days and the cells appeared normal (Fig. 6D,H). We further investigated whether TA or PG might influence the invasive behavior of CRC cells; however, neither substance had a significant impact on invasion (data not shown). 

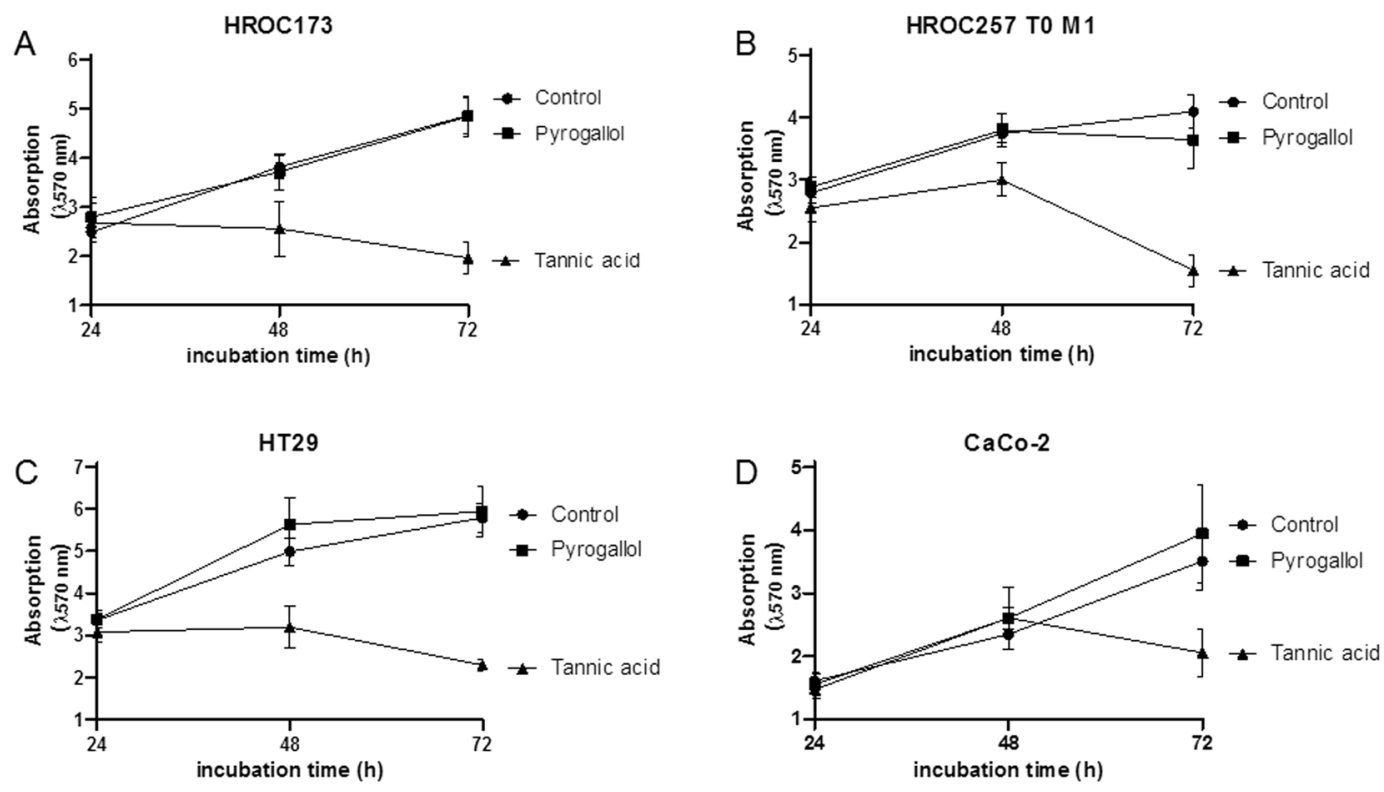

Figure 2. Crystal violet staining of different cell lines treated with $100 \mu \mathrm{M}$ TA or PG. TA, but not its metabolite PG, reduced cell growth. Quantitative analysis of adherent cells was done by crystal violet staining after 24, 48 and $72 \mathrm{~h}$ of incubation. Untreated cells (control) were used as controls. Results show data of three independent experiments. Mean \pm SEM.

Taken together, TA, but not its degradation product PG, is toxic on CRC cell lines and induces senescence in residual cells.

S. gallolyticus UCN34, but not Sii, degrades TA. The strain Sgg UCN34 contains two genes for tannase (GALLO_1609 and GALLO_0933) as well as two decarboxylase genes ${ }^{10}$, important for TA degradation. We confirmed tannase activity of $S g g$ UCN34 by a spectrophotometric method ${ }^{33}$, using the Sii strain as a negative control. This method uses methyl gallate as substrate degraded by bacterial tannase, whereby gallic acid will be released and detected at A440 nm. Figure 7A shows that Sgg, but not Sii, produced significant higher amounts of gallic acid, comparing to control samples without bacteria.

TA was described to exert strong antimicrobial activity against bacteria without tannase, thus growth of $S g g$ and $\mathrm{Sii}$ in the presence of high TA concentrations was tested. However, TA had no influence on Sii or Sgg growth at concentrations of $1000 \mu \mathrm{M}$ (Fig. 7B).

TA in solution can also be detected at $310 \mathrm{~nm}^{34}$. When bacteria were incubated in a $1000 \mu \mathrm{M}$ TA solution, a decrease of absorption (about 50\%) could be detected after 24 hours of incubation with Sgg (Fig. 7C). After $48 \mathrm{~h}$ the TA content was reduced to $15 \%$ in the presence of $S g g$, and to $43 \%$ in the presence of Sii, whereby in the presence of buffer the TA content was reduced to $67 \%$ (Fig. 7C). These data indicate that the TA-solution is relatively stable in the absence of bacteria, and actively degraded by $S g g$.

Degradation of TA by Sgg obliterated its toxic effect on tumor cells. As TA can be degraded by $S g g$ we next tested whether this might protect CRC cells from killing. To address this experimentally, TA was incubated with Sgg, Sii or buffer, to reduce the TA concentration by the bacteria. After incubation, bacterial supernatants were sterilized by filtration and added to different tumor cell lines. TA alone was used as a positive control for the toxic effect. Additionally, bacterial supernatants without TA served as controls. CRC biomass was quantified by crystal violet staining after $72 \mathrm{~h}$ of incubation. As shown before, treatment with $100 \mu \mathrm{M}$ TA significantly reduced the biomass in all cell lines (Fig. 8). However, this effect was partially abolished when the TA solution was pretreated with $S g g$ bacteria. This effect was not observed after pretreatment with Sii bacteria (Fig. 8). Intriguingly, bacterial supernatant (without TA) from both species stimulated growth of the HROC173 cell line significantly (Fig. 8A). These data additionally suggest a tumor growth-promoting effect of bacterial compounds. Taken together, degradation of TA by Sgg bacteria abrogates its toxic effect on two tumor cell lines.

\section{Discussion}

Tannic acids (TA) widely occur in common food such as berries, grapes, mangoes, and nuts, but also in a variety of beverages such as coffee, tea or red wine for a review see ${ }^{35}$. TA are additionally extensively used as clarifying and refining agent in food. Thus, a daily intake of sufficient amounts of TA by most of the humans is very likely.

In an experimental mouse model, it has been demonstrated that very low dose dietary TA administration prevented animals against spontaneous hepatic neoplasm development. The TA amount consumed daily by each 

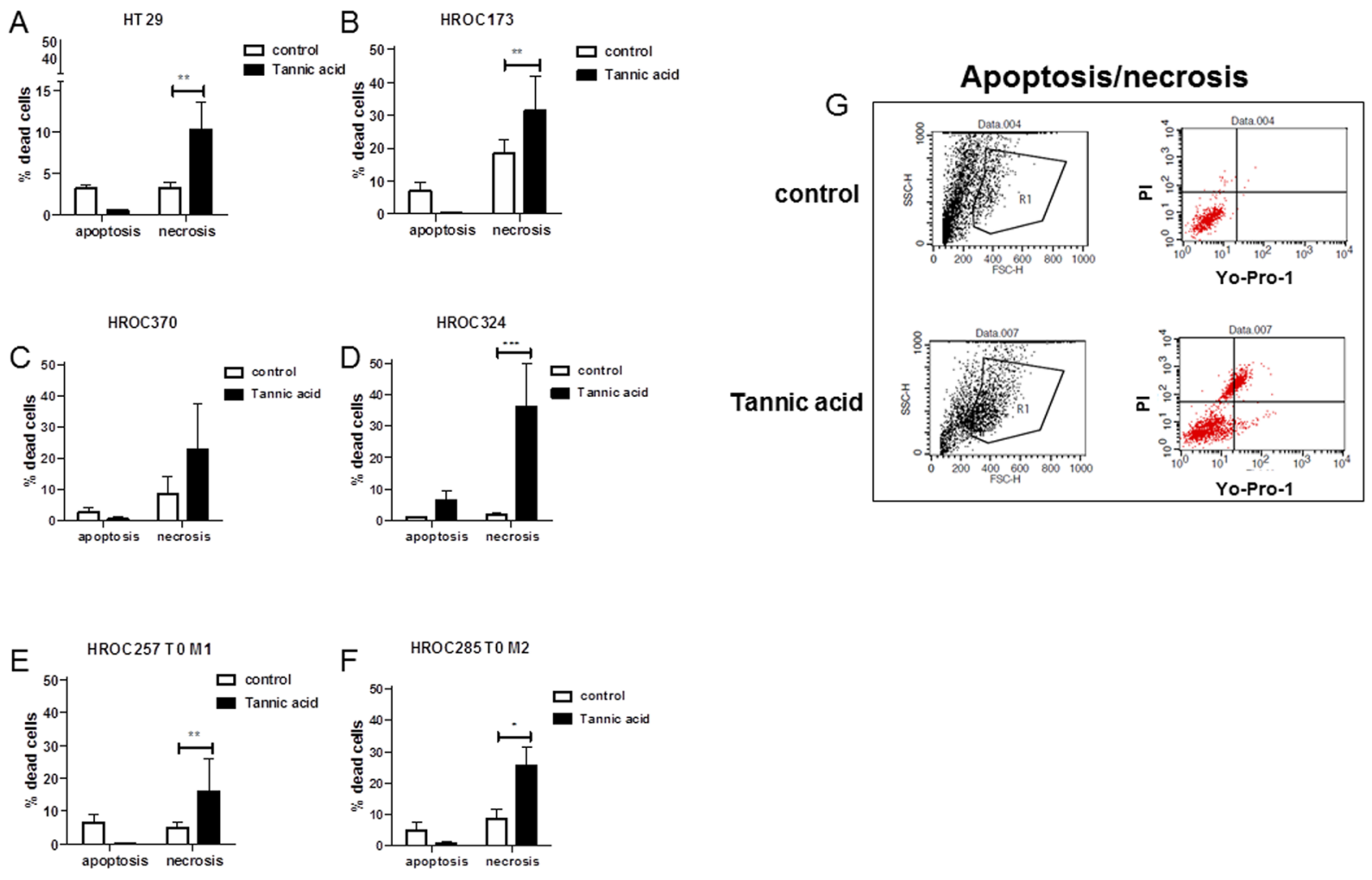

Figure 3. Apoptosis and necrosis measured after treatment with TA. $1 \times 10^{4}$ cells were seeded and after overnight incubation treated with $100 \mu \mathrm{M}$ TA. Apoptosis and necrosis was determined via flow cytometry $48 \mathrm{~h}$ after treatment. (A-F) Results show data of three independent experiments. Mean \pm SD, *p $<0.05, * * p<$ $0.0065, * * * \mathrm{p}=0.0006$; two-tailed t-test $(\mathbf{G})$ Representative flow cytometry dot blots of HROC173 cells either being untreated (control, upper panel) or treated with TA (lower panel).

A

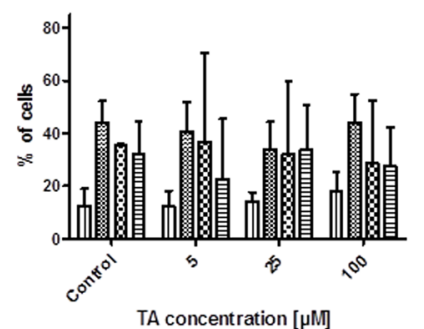

B HROC257 TO M1 24h

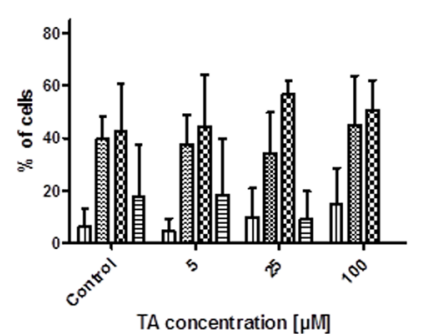

HROC173 72h

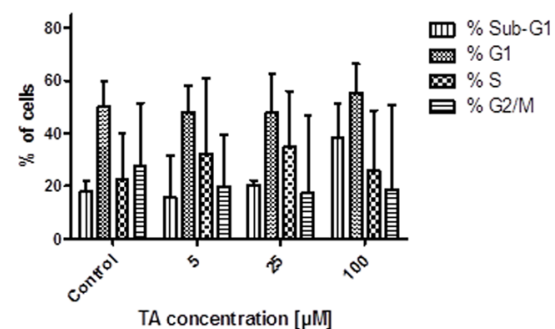

HROC257 TO M1 72h
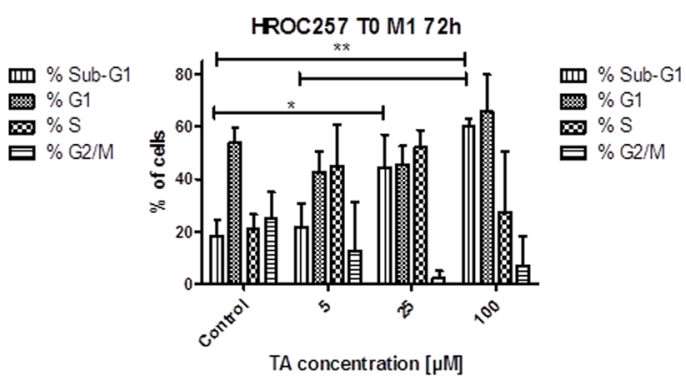

Figure 4. Cell cycle analysis after treatment with TA. $1 \times 10^{4}$ cells of (A) HROC173 and (B) HROC257 T0 M1 were seeded and after overnight incubation treated with increasing TA concentrations. Cell cycle phases as well as numbers of cells with Sub-G1 DNA were examined at 24 and $72 \mathrm{~h}$ after treatment. Residual cells were mainly arrested in G1 or G2/M-phase. Results show data of three independent experiments. Mean $\pm \mathrm{SD}$, *p $<0.05$; $* * \mathrm{p}<0.01$; one way ANOVA on ranks (Bonferroni's Multiple Comparison Test). (C) Representative flow cytometry blots of HROC173 cells either being untreated (control, upper panel) or treated with TA (middle and lower panel) for 72 hours. 


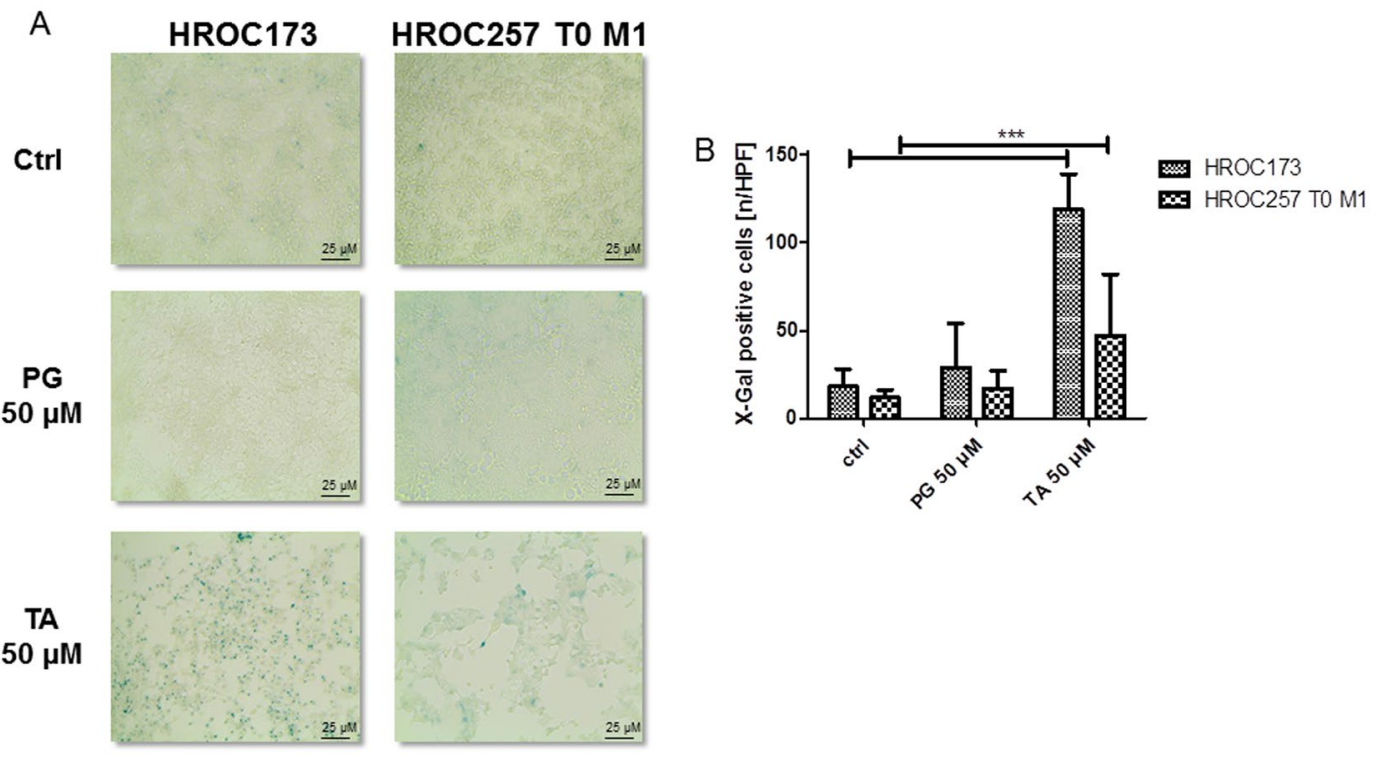

Figure 5. Detection of senescence in HROC173 and HROC257 T0 M1 cells after incubation with $50 \mu \mathrm{M}$ TA. $1 \times 10^{4}$ cells were seeded and after overnight incubation treated with $50 \mu \mathrm{M}$ TA or PG for 5 days. Senescent cells were detected by blue color after beta-galactosidase assay. Treated cell show increased numbers of betagalactosidase-positive cells. (A) Representative light microscopic images. Original magnification 10x. (B) X-Gal quantification. HPF - high power field; Mean $\pm \mathrm{SD}$, ***p $<0.0001$; two-tailed t-test.

mouse in this study corresponded to the human situation, and further support the strong anti-carcinogenic effect of $\mathrm{TA}^{36}$.

In our study, we examined the direct effects of TA on a panel of patient-derived as well as long-term cultured CRC cell lines. TA induced a biphasic, but dose-dependent growth inhibiting effect in all CRC cell lines tested, supporting recent findings in which TA was described to exert anti-proliferative activity on numerous cancers. TA affected migratory potential in all cell lines, and cytotoxicity was mainly due to necrosis with additional senescence induction in residual cells. Mechanistically, this is likely attributable to local amino acid starvation that triggers cancer cell senescence. This effect is well-described for other amino-acid degrading enzymes, such as the bacterial arginine deiminase ${ }^{29,37}$. TA increases the production of reactive oxygen species by altering the redox balance in the cell. This finally induces cell cycle arrest as described for HCT116 cells ${ }^{38}$, supported by our own observations.

TA is thus considered a potential anticancer agent ${ }^{39-41}$, with additional ability to act as chemosensitizer ${ }^{42}$. The latter is a characteristic quite common for other polyphenols as well. The selective antitumoral efficacy of TA was further shown here by lacking cytotoxicity of PG, a degradation product of TA. While this substance was found to exert growth-inhibiting and pro-apoptotic against breast cancer cells in vitro, viability as well as migratory activity of CRC was not substantially affected ${ }^{43}$. Moreover, the natural concentration of PG in fruits and vegetables is generally low, but likely increases by tannin-degrading bacteria, such as $S g g^{21}$.

Apart from the therapeutic effect of TA, a recent study even proposed this substance as a promising pyruvate kinase isoenzyme M2 inhibitor for CRC prevention ${ }^{39}$. Still, clinical evidence of dietary polyphenols as chemopreventive compounds is scarce and at least partially attributable to the fact that TA concentrations in the gastrointestinal tract are hardly measurable and backtracked to mediate a direct tumor growth inhibitory effect.

TA possess numerous pharmacological and thus biologically relevant characteristics, such as anti-inflammatory and bacteriostatic activity with MIC values between 0.012 and $1 \mathrm{~g} / \mathrm{l}^{44}$. Here, we show that $S g g$, as well as Sii are able to grow in the presence of high TA concentrations $(1000 \mu \mathrm{M} \triangleq 1701 \mathrm{~g} / \mathrm{l})$. However, our data indicate that only Sgg actively degrades TA, supporting earlier reports ${ }^{45}$. Physiologically, this characteristic is considered an adaptive mechanism to withstand stress conditions associated with the presence of these phenolic compounds.

While TA may have potent antitumoral activity, Sgg is a common and selective gut colonizer of CRC patients. This high prevalence of $S g g$ in CRC patients - compared to healthy persons - might be associated with specific conditions created by the tumor, such as increased concentration of bile acids and a slowed food flow. This leads to accumulation of plant-derived fiber carbohydrates and possibly TA, which may represent a favorable microenvironment for establishment and proliferation of $S g g^{10}$.

Whether $S g g$ is a passenger or a driver bacterium has not been completely elucidated, but is just beginning to become clear. Pasquereau-Kotula described a two-hypothesis model, by which Sgg either contributes to CRC development as a consequence of local microbial imbalance or actively accelerates transformation due to high colonization in pre-malignant epithelium along with specific inflammatory responses and increased cell proliferation ${ }^{46}$. Growing evidence supports the former with $S g g$ not being a bona fide pathogen, but likely benefits 
do
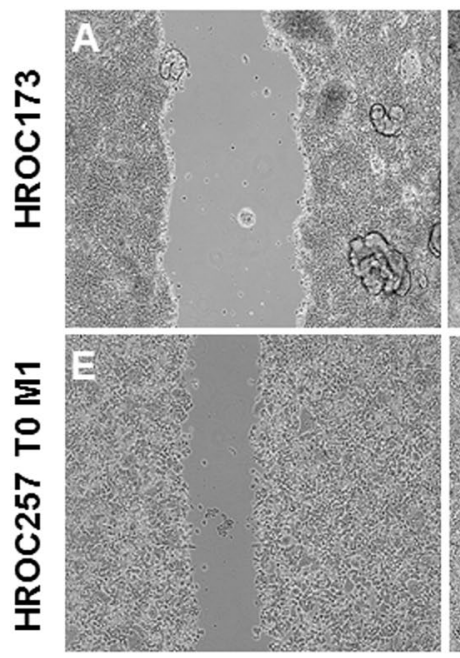

d5 control
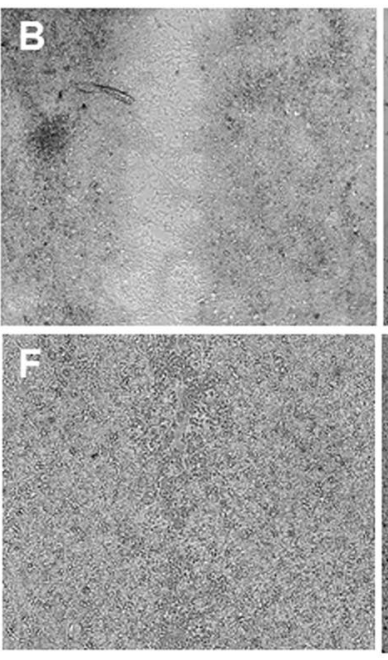

d5 TA
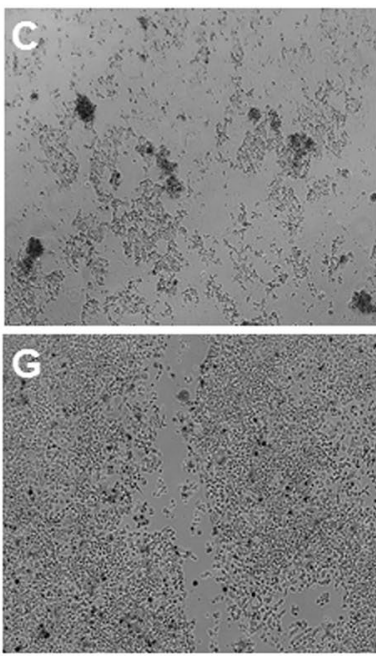

d5 PG
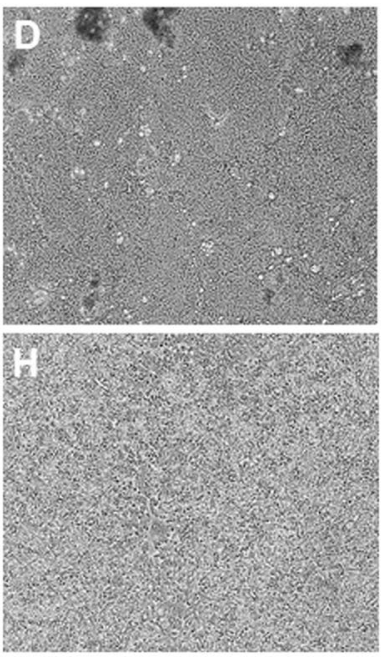

Figure 6. Wound healing assays were performed with HROC173 and HROC257 T0 M1 cells. Representative light microscopic images of migrating tumor cells at day 0 (d0) and day 5 (d5) following incubation with $50 \mu \mathrm{M}$ TA or PG. Original magnification 10x.

A

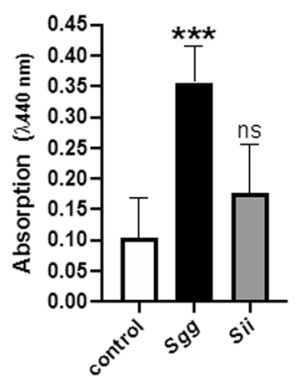

B

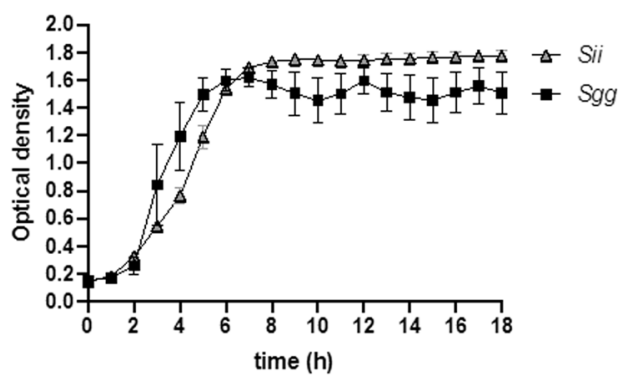

C

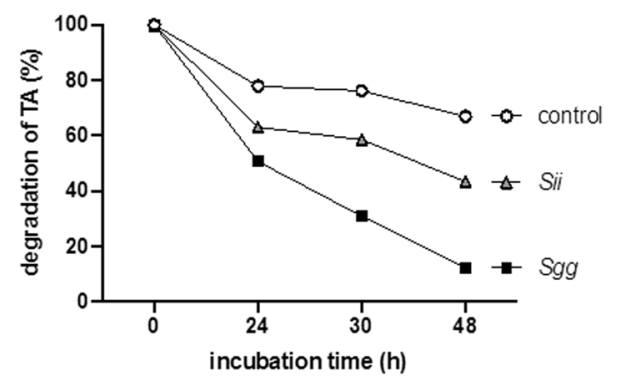

Figure 7. TA degradation and growth of bacteria in the presence of TA (A) Overnight cultures of bacteria $\left(10^{8} \mathrm{CFU} / \mathrm{ml}\right)$ were incubated with $2 \mathrm{mM}$ methylgallate for $24 \mathrm{~h}$ at $37^{\circ} \mathrm{C}$. Buffer without bacteria were used as control. Gallic acid (released by tannase from methylgallate) was oxidized and measured at $440 \mathrm{~nm}$. (B) Growth curve of Sgg or Sii in cell culture medium containing $1000 \mu \mathrm{M}$ TA. The optical density was determined in a Spectramax (C) Overnight cultures of bacteria $\left(10^{8} \mathrm{CFU} / \mathrm{ml}\right)$ or buffer (control) were incubated in $1000 \mu \mathrm{M}$ TA for up to $48 \mathrm{~h}$. Absorption of the original solution was set to $100 \%$. Mean $\pm \mathrm{SD}$, $* * * \mathrm{p}<0.0005$; two-tailed t-test.

from the microenvironment created by preneoplastic glands in the gut ${ }^{9}$. A recent study supports these findings by identifying different interactions of Sgg strains with human colon cancer cells. This finding was confirmed in vivo using the azoxymethane-induced CRC model ${ }^{47}$. The authors suggested a close contact between $\mathrm{Sgg}$ and host cells to be important for mediating growth promoting effects. Our study adds a piece to this and thus broadens our current knowledge on the interaction of $S g g$ with CRC.

Yet, while some gastrointestinal microbes were described to preferentially degrade hydrolyzable tannins (e.g. Lactobacillus plantarum, Lonepinella koalarum and Selenomonas ruminantium, Staphylococcus lugdunensis) almost none of them have been linked to CRC. A recent study identified an active tannase enzyme from the oral pathogen Fusobacterium nucleatum ${ }^{48}$ - only lately described to promote CRC similar to Sgg. Of note, serum anti-Fn antibody IgA combined with carbohydrate antigen 19-9 and carcinoembryonic antigen are reliable screening tools and just as for F. nucleatum ${ }^{49}$, efforts to use $S g g$ antibodies as serum biomarkers are on the way for CRC risk stratification ${ }^{50}$. Hence, such microbial-based approaches will facilitate diagnostic efficacies prospectively.

Summarizing our findings, this study hypothesizes that colonization of CRC by Sgg protects tumor cells against the cytotoxic effects of TA. Detection and elimination of these bacteria - and certainly other TA-degrading microbes - might finally support effective treatment of CRC. Further in vivo studies are necessary to proof this hypothesis. 
A

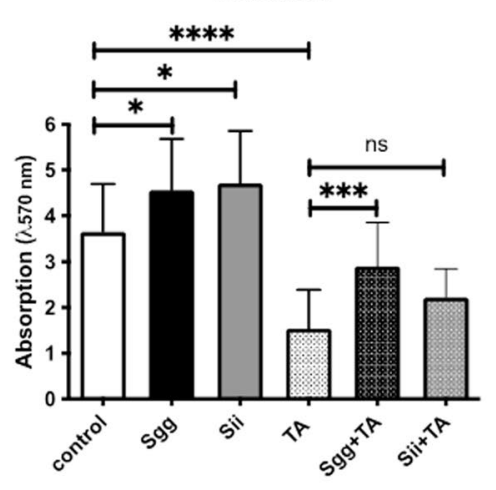

B

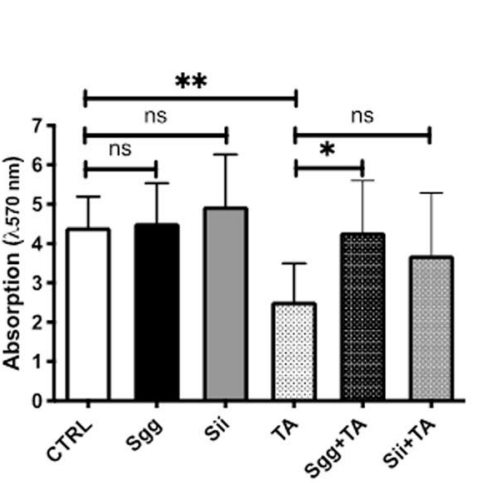

$\mathrm{C}$

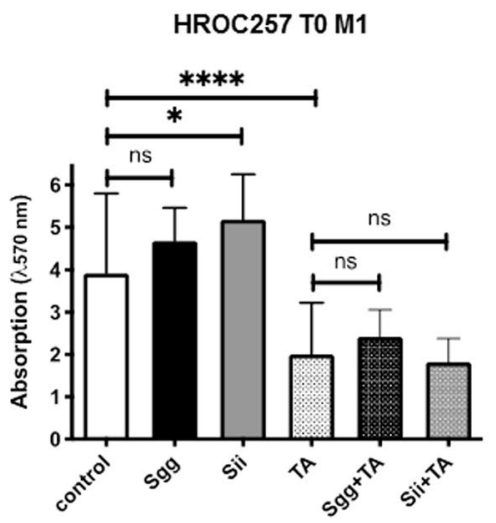

Figure 8. Growth of CRC cells after incubation with bacterial supernatants. TA was incubated with bacteria $(S g g+\mathrm{TA}, \mathrm{Sii}+\mathrm{TA})$ or buffer (TA), for $24 \mathrm{~h}$ to reduce the TA concentration in the solution. Bacteria without TA (Sgg, Sii) were used as negative control. Cells treated with buffer alone were used as control. Bacterial supernatants were sterilized by filtration and added to three different tumor cell lines at final estimated concentration of $100 \mu \mathrm{M}$ TA. Quantitative analysis of adherent cells was done by crystal violet staining after $72 \mathrm{~h}$ of incubation. Results show data of three independent experiments. Mean $\pm \mathrm{SD}$; $\mathrm{p}<0.05, * * \mathrm{p}<0.005, * * * \mathrm{p}$ $<0.0005, * * * * \mathrm{p}<0.0001$; one way ANOVA (Holm-Šídák test).

\section{Conclusions}

This study confirms (I) the cytotoxic activity of tannic acids against colorectal cancer cells and (II) describes a protective role of the tannic acid-degrading bacteria $\mathrm{Sgg}$ most likely providing a growth advantage of colorectal cancer cells. Hence, we here add another piece of evidence for the relevance of the bacterial microenvironment in cancer initiation and most likely also progression. This study constitutes a fundamental basis for upcoming preclinical research to diagnose and on the long run combat cancer.

\section{Data availability}

The datasets used and/or analyzed during the current study are available from the corresponding author on reasonable request.

Received: 3 December 2019; Accepted: 16 February 2020;

Published online: 13 March 2020

\section{References}

1. Jans, C., Meile, L., Lacroix, C. \& Stevens, M. J. A. Genomics, evolution, and molecular epidemiology of the Streptococcus bovis/ Streptococcus equinus complex (SBSEC). Infect. Genet. Evol. 33, 419-436 (2014).

2. Schlegel, L., Grimont, F., Ageron, E., Grimont, P. A. D. \& Bouvet, A. Reappraisal of the taxonomy of the Streptococcus bovis/ Streptococcus equinus complex and related species: description of Streptococcus gallolyticus subsp. gallolyticus subsp. nov., S. gallolyticus subsp. macedonicus subsp. nov. and S. gallolyticus subsp. pasteurianus subsp. nov. Int. J. Syst. Evol. Microbiol. 53, 631-645 (2003).

3. Jans, C. et al. Phylogenetic, epidemiological and functional analyses of the Streptococcus bovis/Streptococcus equinus complex through an overarching MLST scheme. BMC Microbiol. 16, 117 (2016).

4. Hoen, B. et al. Emergence of endocarditis due to group D streptococci: findings derived from the merged database of the International Collaboration on Endocarditis. Eur. J. Clin. Microbiol. Infect. Dis. 24, 12-16 (2005).

5. Boleij, A., Schaeps, R. M. J. \& Tjalsma, H. Association between Streptococcus bovis and colon cancer. J. Clin. Microbiol. 47, 516-516 (2009).

6. Klein, R. S. et al. Association of Streptococcus bovis with carcinoma of the colon. N. Engl. J. Med. 297, 800-802 (1977).

7. Abdulamir, A. S., Hafidh, R. R. \& Bakar, F. A. Molecular detection, quantification, and isolation of Streptococcus gallolyticus bacteria colonizing colorectal tumors: inflammation-driven potential of carcinogenesis via IL-1, COX-2, and IL-8. Mol. Cancer 9 , $249(2010)$.

8. Kumar, R. et al. Streptococcus gallolyticus subsp. gallolyticus promotes colorectal tumor development. PLoS Pathog. 13, e1006440 (2017).

9. Aymeric, L. et al. Colorectal cancer specific conditions promote Streptococcus gallolyticus gut colonization. Proc. Natl Acad. Sci. 115, E283-E291 (2018).

10. Rusniok, C. et al. Genome sequence of Streptococcus gallolyticus: insights into its adaptation to the bovine rumen and its ability to cause endocarditis. J. Bacteriol. 192, 2266-2276 (2010).

11. Osawa, R., Fujisawa, T. \& Sly, L. Streptococcus gallolyticus sp. nov.; gallate degrading organisms formerly assigned to Streptococcus bovis. Systematic and applied microbiology (1995).

12. Galvez, J. M. G., Riedl, B. \& Conner, A. H. Analytical Studies on Tara Tannins. Holzforschung - International. J. Biology, Chemistry, Phys. Technol. Wood 51, 235-243 (1997).

13. Redwane, A. et al. Larvicidal activity of extracts from Quercus lusitania var. infectoria galls (Oliv.). J. Ethnopharmacol. 79, 261-263 (2002).

14. Al-Ayyoubi, S. \& Gali-Muhtasib, H. Differential apoptosis by gallotannin in human colon cancer cells with distinct p53 status. Mol. Carcinog. 46, 176-186 (2007).

15. Al-Halabi, R. et al. Gallotannin inhibits NFkB signaling and growth of human colon cancer xenografts. Cancer Biol. Ther. 12, 59-68 (2011). 
16. Erdèlyi, K. et al. Gallotannin inhibits the expression of chemokines and inflammatory cytokines in A549 cells. Mol. Pharmacol. 68, 895-904 (2005).

17. Urueña, C. et al. Gallotannin-rich Caesalpinia spinosa fraction decreases the primary tumor and factors associated with poor prognosis in a murine breast cancer model. BMC Complement. Altern. Med. 13, 74 (2013).

18. Naasani, I. et al. Blocking telomerase by dietary polyphenols is a major mechanism for limiting the growth of human cancer cells in vitro and in vivo. Cancer Res. 63, 824-830 (2003).

19. Cosan, D. T. et al. Effects of various agents on DNA fragmentation and telomerase enzyme activities in adenocarcinoma cell lines. Mol. Biol. Rep. 38, 2463-2469 (2011).

20. Savelyev, N. et al. Comprehensive analysis of telomerase inhibition by gallotannin. Oncotarget 9, 18712-18719 (2018).

21. de Felipe, F. L. Bioactive compounds produced by gut microbial tannase: implications for colorectal cancer development. 1-4, https://doi.org/10.3389/fmicb.2014.00684/abstract (2014).

22. Papadimitriou, K. et al. Comparative genomics of the dairy isolate Streptococcus macedonicus ACA-DC 198 against related members of the Streptococcus bovis/Streptococcus equinus complex. BMC Genomics 15, 272 (2014).

23. Chamkha, M., Patel, B. K. C., Traore, A., Garcia, J.-L. \& Labat, M. Isolation from a shea cake digester of a tannin-degrading Streptococcus gallolyticus strain that decarboxylates protocatechuic and hydroxycinnamic acids, and emendation of the species. Int. J. Syst. Evol. Microbiol. 52, 939-944 (2002).

24. Jiménez, N. et al. Genetic and biochemical approaches towards unravelling the degradation of gallotannins by Streptococcus gallolyticus. Microb. Cell Fact. 13, 154 (2014).

25. Maletzki, C. et al. Host defense peptides for treatment of colorectal carcinoma - a comparative in vitro and in vivo analysis. Oncotarget 5, 4467-4479 (2014).

26. Isenring, J. et al. Streptococcus gallolyticus subsp. gallolyticus endocarditis isolate interferes with coagulation and activates the contact system. Virulence $9,1-31$ (2017).

27. Isenring, J. et al. Streptococcus gallolyticus subsp. gallolyticus endocarditis isolate interferes with coagulation and activates the contact system. Virulence, 1-14, https://doi.org/10.1080/21505594.2017.1393600 (2017).

28. Fiedler, T. et al. Arginine deprivation by arginine deiminase of Streptococcus pyogenescontrols primary glioblastoma growth in vitroand in vivo. Cancer Biol. Ther. 16, 1047-1055 (2015).

29. Maletzki, C. et al. Establishment and characterization of cell lines from chromosomal instable colorectal cancer. World J. Gastroentero 21, 164-176 (2015).

30. Maletzki, C. et al. Deciphering molecular mechanisms of arginine deiminase-based therapy - Comparative response analysis in paired human primary and recurrent glioblastomas. Chemico-Biological Interact. 278, 179-188 (2017).

31. Osawa, R. Formation of a clear zone on tannin-treated brain heart infusion agar by a Streptococcus sp. isolated from feces of koalas. Appl. Environ. Microbiol. 56, 829-831 (1990).

32. Al-Halabi, R. et al. Gallotannin is a DNA damaging compound that induces senescence independently of p53 and p 21 in human colon cancer cells. Mol. Carcinog. 54, 1037-1050 (2015).

33. Osawa, R. \& Walsh, T. P. Visual reading method for detection of bacterial tannase. Appl. Environ. Microbiol. 59, 1251-1252 (1993).

34. Franiau, R. \& Mussche, R. Quantitative Determination of Gallic Acid in Tannic Acid by Thin-Layer Chromatography. J. Inst. Brew. 78, 450-\& (1972)

35. Mingshu, L., Kai, Y., Qiang, H. \& Dongying, J. Biodegradation of gallotannins and ellagitannins. J. Basic. Microbiol. 46, 68-84 (2006).

36. Nepka, C. et al. Chemopreventive activity of very low dose dietary tannic acid administration in hepatoma bearing $\mathrm{C} 3 \mathrm{H}$ male mice. Cancer Lett. 141, 57-62 (1999).

37. Ni, Y., Schwaneberg, U. \& Sun, Z.-H. Arginine deiminase, a potential anti-tumor drug. Cancer Lett. 261, 1-11 (2008).

38. Cairney, C. J. et al. A 'synthetic-sickness' screen for senescence re-engagement targets in mutant cancer backgrounds. PLoS Genet. 13, e1006942 (2017).

39. Yang, P. et al. Tannic acid directly targets pyruvate kinase isoenzyme M2 to attenuate colon cancer cell proliferation. Food Funct. 9 , $5547-5559$ (2018).

40. Nie, F. et al. Apoptotic effect of tannic acid on fatty acid synthase over-expressed human breast cancer cells. Tumour Biol. 37, 2137-2143 (2016).

41. Karakurt, S. \& Adali, O. Tannic Acid Inhibits Proliferation, Migration, Invasion of Prostate Cancer and Modulates Drug Metabolizing and Antioxidant Enzymes. Anticancer. Agents Med. Chem. 16, 781-789 (2016).

42. Li, H., Krstin, S. \& Wink, M. Modulation of multidrug resistant in cancer cells by EGCG, tannic acid and curcumin. Phytomedicine 50, 213-222 (2018).

43. Nemec, M. J. et al. Pyrogallol, an absorbable microbial gallotannins-metabolite and mango polyphenols (Mangifera Indica L.) suppress breast cancer ductal carcinoma in situ proliferation in vitro. Food Funct, https://doi.org/10.1039/c6fo00636a (2016).

44. Scalbert, A. Antimicrobial properties of tannins. Phytochemistry 30, 3875-3883 (1991).

45. O’Donovan, L. \& Brooker, J. D. Effect of hydrolysable and condensed tannins on growth, morphology and metabolism of Streptococcus gallolyticus (S. caprinus) and Streptococcus bovis. Microbiology 147, 1025-1033 (2001).

46. Pasquereau-Kotula, E., Martins, M., Aymeric, L. \& Dramsi, S. Significance of Streptococcus gallolyticus subsp. gallolyticus Association With Colorectal Cancer. Front. Microbiol. 9, 683 (2018).

47. Kumar, R., Herold, J. L., Taylor, J., Xu, J. \& Xu, Y. Variations among Streptococcus gallolyticus subsp. gallolyticus strains in connection with colorectal cancer. Sci Rep 1-10, https://doi.org/10.1038/s41598-018-19941-7 (2018).

48. Tomás-Cortázar, J. et al. Identification of a highly active tannase enzyme from the oral pathogen Fusobacterium nucleatum subsp. polymorphum. Microb. Cell Fact. 17, 33-10 (2018).

49. Yang, Z. \& Ji, G. Fusobacterium nucleatum-positive colorectal cancer. Oncol. Lett. 18, 975-982 (2019).

50. Butt, J. et al. Association of Streptococcus gallolyticus subspecies gallolyticus with colorectal cancer: Serological evidence. Int. J. Cancer 138, 1670-1679 (2016).

\section{Acknowledgements}

The authors would like to thank Christoph Jans and Pierre Renault for providing the S. infantarius isolate. $\mathrm{SOH}$ was supported by the Federal Excellence Initiative of Mecklenburg Western Pomerania and European Social Fund (ESF) Grant KoInfekt (ESF_14-BM-A55-00xx_16), and by a grant from the Deutsche Forschungsgemeinschaft (OE547/4-1). The study was supported by a grant from the Medical Faculty of the University of Rostock in the framework of the FORUN program 2018. CM was supported by grants from the Deutsche Forschungsgemeinschaft (MA5799/2-1 and MA5799/2-2). Purchase of the BD Accuri C6 was kindly supported by the EU-EFRE (European Funds for Regional Development) program and funds from the University Medicine Rostock awarded to BK. This project was partially supported by the Safe Dairy consortium funded by ERAfrica/PASRES (https://www.erafrica.eu/) “New Ideas” project No ERAfrica_NI_021. 


\section{Author contributions}

S.O.H. and C.M. designed the study, interpreted results and wrote the manuscript: V.M., L.T.N., L.D. and J.K. performed experiments, analyzed data and prepared figures. B.K. critically revised the manuscript.

\section{Competing interests}

The authors declare no competing interests.

\section{Additional information}

Correspondence and requests for materials should be addressed to S.O.-H. or C.M.

Reprints and permissions information is available at www.nature.com/reprints.

Publisher's note Springer Nature remains neutral with regard to jurisdictional claims in published maps and institutional affiliations.

(c) (i) Open Access This article is licensed under a Creative Commons Attribution 4.0 International License, which permits use, sharing, adaptation, distribution and reproduction in any medium or format, as long as you give appropriate credit to the original author(s) and the source, provide a link to the Creative Commons license, and indicate if changes were made. The images or other third party material in this article are included in the article's Creative Commons license, unless indicated otherwise in a credit line to the material. If material is not included in the article's Creative Commons license and your intended use is not permitted by statutory regulation or exceeds the permitted use, you will need to obtain permission directly from the copyright holder. To view a copy of this license, visit http://creativecommons.org/licenses/by/4.0/.

(C) The Author(s) 2020 